\title{
Patterns And Correlates Of Substance Use: Cross Sectional Exploratory Study Among Health Care Workers In Bungoma County, Kenya
}

Titus Kipchirchir Kolongei ( $\nabla$ tkolongei@gmail.com )

Kenyatta University https://orcid.org/0000-0002-0030-2901

Justus Osero

Kenyatta University

Albert Gachau

Kenyatta University

\section{Short Report}

Keywords: Substance Use, abuse, dependence, patterns, correlates, lifetime use

Posted Date: March 3rd, 2020

DOI: https://doi.org/10.21203/rs.3.rs-15770/v1

License: (c) (i) This work is licensed under a Creative Commons Attribution 4.0 International License.

Read Full License 
ORIGINAL PAPER;

PATTERNS AND CORRELATES OF SUBSTANCE USE: CROSS SECTIONAL EXPLORATORY STUDY AMONG HEALTH CARE WORKERS IN BUNGOMA COUNTY, KENYA

\section{CORRESPONDING AUTHOR}

\section{KOLONGEI, KIPCHIRCHIR TITUS}

Department of Community Health \& Epidemiology, Kenyatta University, Kenya

\section{CO- AUTHORS}

2. Osero Justus O. S. Lecturer, Department of Community Health \& Epidemiology, Kenyatta University Kenya

\section{Gachau G. Albert}

Department of Pathology, Kenyatta University Kenya

\section{Authors Affiliations}

Address: ${ }^{1}$ Kenyatta University Department of Community Health and Epidemiology Box 43844-00100 GPO Nairobi Kenya

Email; tkolongei@gmail.com Corresponding Author

Address: ${ }^{2}$ Kenyatta University Department of Community Health and Epidemiology Box Box 43844-00100 GPO Nairobi Kenya Email; oseroc@ku.ac.ku Co-Author

Address: ${ }^{3}$ Kenyatta University Department of Pathology Box 43844-00100 GPO Nairobi Kenya

Email; oseroc@ku.ac.ku Co-Author

FEBRUARY, 2020 


\section{TABLE OF CONTENTS}

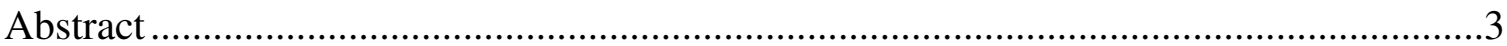

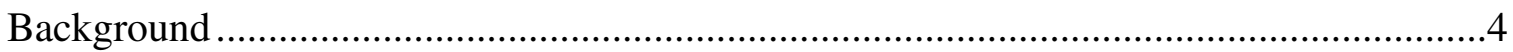

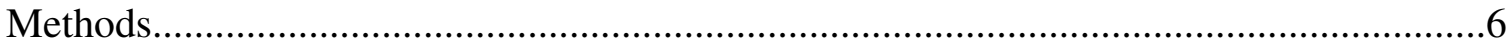

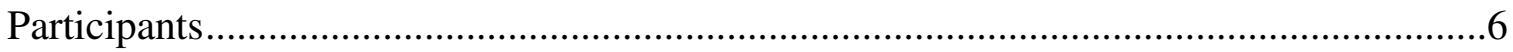

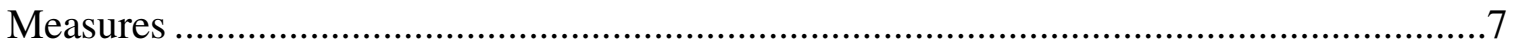

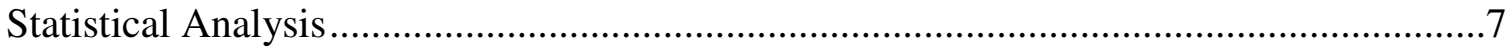

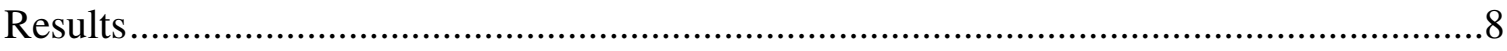

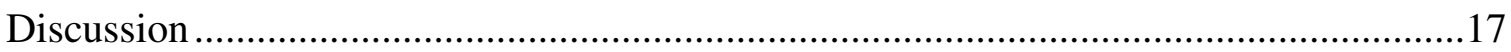

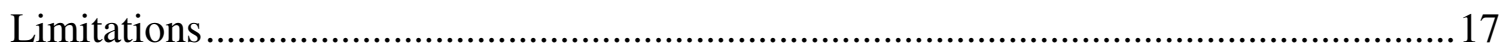

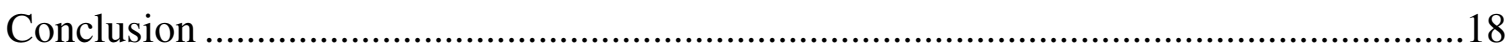

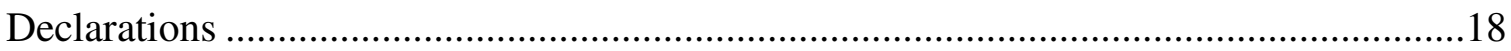

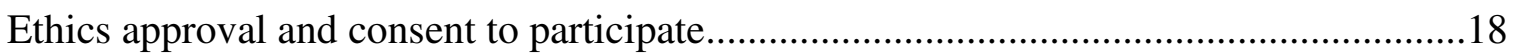

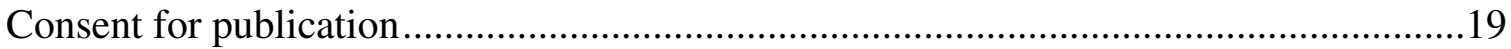

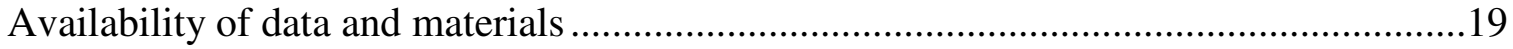

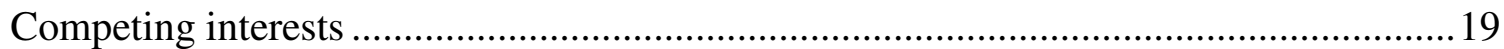

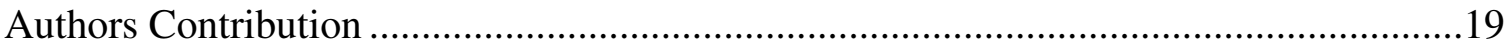

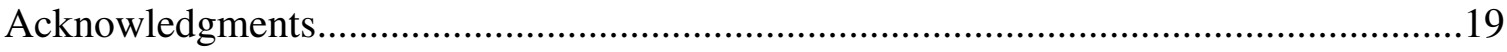

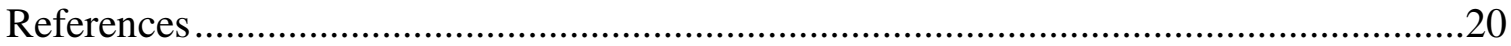




\begin{abstract}
Background: This was a cross sectional exploratory study that examined data obtained from health care workers on substance use in Bungoma County Kenya.

Methods: This was a cross sectional exploratory study in selected health facilities in three sub counties of Bungoma County. This study used a two-stage cluster sampling technique and systematic sampling to select the respondents. The study sample was $(\mathrm{N}=237)$ among health care workers in selected facilities in 3 sub counties of Bungoma county .The study response rate was $96.3 \%(237 / 247)$. Self-reported data on substance use during their lifetime, use in the past 12 months and past 30 days was used as key parameters to determine patterns and correlates of substance
\end{abstract}

Results: As compared with females, males were found to have a greater like hood of substance use, having family member with a history of substance use and a colleague who uses substances were key predictors for substance use. Substance use prevalence without generalization to the population of Health care workers (HCWs) in this study shows a high prevalence of lifetime substance use $(35.02,29.17$ - 41.36) concurs with findings in a study in Machakos and Nairobi (Mokaya et al 2018). Alcohol had the highest lifetime prevalence rate $(33 \%)$

Conclusion; Alcohol use among HCW had the highest prevalence with socio-demographic factors on gender, family and peer influence associated with substance use among health workers. The study findings suggest preventive interventions against substance use are required at family level and among peers. Further research is needed on substance abuse, dependence, reasons for substance use and how it affects health workers performance

Keywords: Substance Use, abuse, dependence, patterns, correlates, lifetime use 


\section{Background}

Substance use is defined as the practice of using at least one of the substances such as alcohol, cigarettes, and licit or illicit drugs with the aim of enjoying the pleasurable effects of the psychoactive properties which comes with associated risks of addiction [1]

Substance abuse on the other hand is defined as the harmful or hazardous use of psychoactive substances, including alcohol and/or illicit drugs in a manner that jeopardizes ones health despite knowledge of its dangers. Abuse, may be for both licit and illicit substances and may lead to substance use disorder (SUD) such as dependence which is a compulsive craving behaviour that persists despite known consequences [2]

Substance use is a global problem causing 39 deaths per 100000 population out of which 35 deaths are attributable to alcohol use while four are attributable to illicit drug [3]

There is an emergent epidemic of tobacco, heroine and alchohol use among adoloscent in Sub-Saharan Africa (Olawole-Isaac, et al., 2018) with illegal substance consumption responsible for 37,000 people dying annually from illegal drug consumption related illnesses [4]

The estimate of substance use among adolescents in Sub-Saharan Africa was found to be 41.6\% (55 CI 31.3-51.9) with Central Africa taking the lead with 55.5\% (95\%-CI-53-58) followed by East Africa with 48.99\%(95\%-CI-28.8-69.2) and the least in Southern Africa at $37 \%(95 \%$ CI $16.1-57.8)$ [5]

The Government of Kenya acknowledged substance abuse as a matter of national concern, and through a Legal Notice established the National Agency for Coordination of Drug \& Substance abuse tasked with the responsibility to spearhead the campaign against substance 
use (NACADA, 2009). The Ministry of health indicate that the most commonly used drugs in Kenya are nicotine,alchohol and cannabis. [6]

Substance abuse in Kenya has snowballed and manifested itself in different facets in the socio-economic arena. [7] In the recent past, 59\% of employees in Kenya had taken alcohol with $25 \%$ being hospitalized due to alcohol related complications. [8]

A healthcare personnel survey conducted in 2005 in Kenya, found out that four in ten healthcare personnel, had drunk alcohol with an estimate $13 \%$ of health personnel in virtually all provinces except North Eastern province being consumers of alcohol [8]

This is a pointer to a pervasive and silent problem that poses the danger of negatively affecting not only the health and well-being of health workers but have detrimental effects in terms of employee's performance and productivity, yet, health professionals have an ethical responsibility to offer the best available medical care to their patients [9]

However, there is limited data on the socio-demographic and psycho-social factors influencing involvement in substance use, prevalence rates, patterns and types of substances use and the accessibility of substance by health workers.

Substance use problem if not addressed poses the danger of abuse and dependence negatively affect efficiency of employees in their work performance [10] bringing with it serious socioeconomic barriers [8] and eventually become an immense challenge to growth and development [11]

Recent studies, indicate the prevalence of substance abuse not higher in healthcare professionals (HPs) than the general population, however, given the obligation health workers owes to the public, any impairment due to substance use disorder among them could 
place the public at increased risk due to errors health workers could perform while proving treatment [12]

Therefore this study was the first step in obtaining in-depth information on the patterns and correlates of substance use aimed to facilitate the development of tailor made educational and intervention strategies.

The study was conducted in health facilities in three selected sub counties of Bungoma County. It was reported as the county with the highest access to traditional liquor [13] and an upsurge in use of traditional liquor (busaa) and chang'aa [6]. Also recent study found $90 \%$ of household having at least one member who abuse one substance. [14]

The purpose of the study was to determine patterns and correlates of substance use among health workers in Bungoma County, Kenya. The specific objectives was to determine the socio-demographic and physco-social factors associated with substance use; estimate the prevalence of substance use and identify the pattern of substance use.

\section{Methods}

\section{Participants}

This study was carried out in 21 health facilities in three sub counties of Bungoma county. Data for this study was obtained through a cross sectional study among health care workers. Study participants were enlisted using systematic random sampling and interviewed between February-March 2019. Seven health facilities( composed of 1 bigger hospital , 3 health centres and 3 dispensaries) were sampled using lottery method( random generator) Self-administered questionnaires and interview guide were used to collect data on patterns and correlated of substance use 
A total of 237 out of the 246 health workers targeted, completed the questionnaire giving a response rate of $96.3 \%$ with the highest response recorded in Bungoma South $(97.7 \%) \mathrm{Mt}$ Elgon $(97.1 \%)$, and $80.1 \%$ in Bungoma West.

\section{Measures}

The demographic measure included age (spit into age category 20-24-25-29, 30-34 and above 35 years of age), gender, level of education, marital status, occupation, profession, cadre, family history of substance use, work colleague history of substance use and history of stressful events at home and at workplace. Respondent were asked a series of question about substance use in their lifetime, in the past 12 months and in the past 30 days.

\section{Statistical Analysis}

Descriptive analysis was done on the cleaned and complete data and Fischer's exact test and logistic regression model used to test the association of socio-demographic factors and correlates of substance use. Data was cleaned and coded before analysis using STATA version 14.2.Participant characteristics and prevalence of substance use were presented by use of frequencies and percentages for categorical variables.

During the analysis logistic regression was used to examine association between sociodemographic and psych-social factors and correlates of substance use, use in the lifetime, use use in the last 12 months and use in the last 30 days .Bivariate analysis was applied in the first phase. The second phase entailed the use of multivariate regression analysis where variables with a $p<0.2$ in the bivariate phase were fit in the multivariate model with backward regression used to fit the significant variables in the final model. Associations were reported by use of adjusted odds ratios (AOR). Statistical significance was considered for $\mathrm{p}<$ 0.05 using Fischers exact test. 


\section{Results}

Socio-Demographic and Psycho social factors associated with Substance Use

The study found out that sex, use of a substance by family member and use by colleague were determinants of lifetime substance use.

Table 1.1. Participant Socio-Demographic Characteristics

\begin{tabular}{lrcc}
\hline Variables Characteristic $(\mathbf{n = 2 3 7})$ & N & \% \\
\hline Sub County & & & \\
& Bungoma South & 157 & 66.24 \\
& Bungoma West & 14 & 5.91 \\
Sex $(\mathbf{n = 2 3 6 )}$ & Mt. Elgon & 66 & 27.85 \\
& Female & 136 & 57.63 \\
Age $(\mathbf{n = 2 3 1 )}$ & Male & 100 & 42.37 \\
& & & \\
& $19-24$ & 24 & 10.39 \\
Marital Status & $25-34$ & 127 & 54.98 \\
& $35+$ & 80 & 34.63 \\
& & & 22.78 \\
& Single & 54 & 73.42 \\
& Married & 174 & 3.80
\end{tabular}

Education Level $(n=233)$

$\begin{array}{rcc}\text { School Certificate } & 19 & 8.15 \\ \text { Professional Certificate } & 33 & 14.16 \\ \text { Diploma } & 128 & 54.94 \\ \text { Degree } & 32 & 13.73 \\ \text { Postgraduate Diploma } & 17 & 7.30 \\ \text { Postgraduate Degree } & 4 & 1.72 \\ & & \\ \text { Christian } & 220 & 88.9 \\ \text { Muslim } & 15 & 6.36 \\ \text { Other Religion } & 11 & 4.66\end{array}$

Occupation $(\mathbf{n}=231)$

Work unit $(\mathrm{n}=\mathbf{2 2 9})$

$\begin{array}{rcc}\text { Clinical Staff } & 166 & 71.86 \\ \text { Non-Clinical Staff } & 65 & 28.14\end{array}$

$\begin{array}{rcc}\text { Preventive \& Curative } & 168 & 73.36 \\ \text { Diagnostic Care } & 22 & 9.61 \\ \text { Rehabilitative Care } & 10 & 4.37\end{array}$


Auxillary Support Care

Employment Length $(n=224)$

\begin{tabular}{rrcc} 
& $1-5$ yrs & 137 & 61.16 \\
& $6-10$ yrs & 42 & 18.75 \\
Spouse Employment & $11+$ yrs & 45 & 20.09 \\
& & & \\
& Employed & 109 & 62.64 \\
& Unemployed & 65 & 37.36 \\
\hline
\end{tabular}

Table 1.2 Substance use by Socio-demographic \& Psycho-social Factors Associated with Substance use

\begin{tabular}{|c|c|c|c|c|c|c|}
\hline \multirow{2}{*}{$\begin{array}{l}\text { Characteristic } \\
\text { Characteristic }\end{array}$} & \multirow[b]{2}{*}{$\mathbf{N}$} & \multirow[b]{2}{*}{$\begin{array}{c}\text { Prevalence } \\
\mathbf{n}(\%)\end{array}$} & \multicolumn{2}{|c|}{ Bivariate Analysis } & \multicolumn{2}{|c|}{ Multivariate Analysis } \\
\hline & & & uOR $(95 \% \mathrm{CI})$ & $\begin{array}{l}* p \\
\text { value }\end{array}$ & $\operatorname{aOR}(95 \% \mathrm{CI})$ & $\begin{array}{l}* p \\
\text { value }\end{array}$ \\
\hline Sub County & & & & 0.068 & & \\
\hline Bungoma South & 157 & 47 (29.94) & ref. & & ref. & \\
\hline Bungoma West & 14 & $7(50.00)$ & $2.34(0.78-7.04)$ & 0.13 & $\begin{array}{c}1.53(0.35- \\
6.59)\end{array}$ & 0.572 \\
\hline Mt. Elgon & 66 & $29(43.94)$ & $1.83(1.01-3.32)$ & 0.045 & $\begin{array}{c}1.30(0.58- \\
2.88)\end{array}$ & 0.521 \\
\hline Sex & & & & $<0.01$ & & \\
\hline Female & 136 & $31(22.79)$ & $r e f$. & & $r e f$. & \\
\hline Male & 100 & $51(51.00)$ & $3.53(2.01-6.18)$ & & $\begin{array}{l}4.16(2.02- \\
\quad 8.57)\end{array}$ & $\stackrel{<}{0.001}$ \\
\hline Age & & & & 0.772 & & \\
\hline $19-24$ & 24 & $10(41.67)$ & ref. & & & \\
\hline $25-34$ & 127 & $44(34.65)$ & $0.74(0.30-1.81)$ & 0.511 & & \\
\hline $35+$ & 80 & $27(33.75)$ & $0.71(0.28-1.82)$ & 0.478 & & \\
\hline Marital Status & & & & 0.216 & & \\
\hline Single & 54 & 21(38.89) & ref. & & & \\
\hline Married & 174 & $61(35.06)$ & $0.85(0.45-1.59)$ & 0.608 & & \\
\hline Separated/Widowed & 9 & $1(11.11)$ & $0.20(0.02-1.69)$ & 0.138 & & \\
\hline Education Level & & & & 0.307 & & \\
\hline School Certificate & 19 & $3(15.79)$ & ref. & & & \\
\hline $\begin{array}{r}\text { Professional } \\
\text { Certificate }\end{array}$ & 33 & $9(27.27)$ & $2.00(0.47-8.54)$ & 0.349 & & \\
\hline Diploma & 128 & $47(36.72)$ & $3.09(0.86-11.18)$ & 0.085 & & \\
\hline Degree & 32 & $14(43.75)$ & $4.15(1.01-17.11)$ & 0.054 & & \\
\hline Postgraduate Diploma & 17 & $6(35.29)$ & $2.91(0.60-14.18)$ & 0.186 & & \\
\hline Postgraduate Degree & 4 & $2(50.00)$ & $5.33(0.53-54.03)$ & 0.157 & & \\
\hline Religion & & & & 0.895 & & \\
\hline Christian & 220 & $77(35.00)$ & ref. & & & \\
\hline Muslim/Hindu & 15 & $5(33.33)$ & $0.93(0.31-2.82)$ & & & \\
\hline
\end{tabular}


Occupation

Clinical Staff $166 \quad 60(36.14) \quad$ ref.

Non-Clinical Staff $65 \quad 22(33.85) \quad 0.90(0.49-1.65)$

Work unit

Preventive \& Curative $168 \quad 57(33.93) \quad$ ref.

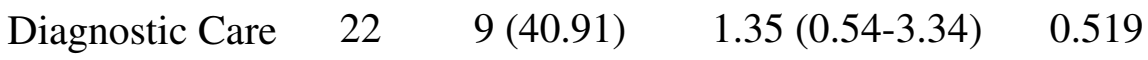

$\begin{array}{lllll}\text { Rehabilitative Care } & 10 & 5(50.00) & 1.95(0.54-7.00) & 0.308\end{array}$

$\begin{array}{lllll}\text { Auxiliary Support } & 29 & 8(27.59) & 0.74(0.31-1.78) & 0.503\end{array}$

Significant results are presented in bold fonts

$\mathrm{uOR}=$ Unadjusted Odd Ratio $\mathrm{aOR}=$ Adjusted Odd Ratio

* Fischer exact test

Table 1. 3. Substance use and Socio-demographic \& Physco-social factors

\begin{tabular}{|c|c|c|c|c|c|c|}
\hline \multicolumn{3}{|l|}{ Characteristic } & \multicolumn{2}{|c|}{ Bivariate Analysis } & \multicolumn{2}{|c|}{ Multivariate Analysis } \\
\hline Characteristic & $\mathbf{N}$ & $\begin{array}{c}\text { Prevalence } \\
\text { n(\%) }\end{array}$ & uOR $(95 \% \mathrm{CI})$ & $\begin{array}{c}* p \\
\text { value }\end{array}$ & aOR $(95 \% \mathrm{CI})$ & $\begin{array}{l}* p \\
\text { value }\end{array}$ \\
\hline Employment Length & & & & 0.817 & & \\
\hline $1-5 \mathrm{yrs}$ & 137 & $45(32.85)$ & ref. & & & \\
\hline $6-10 \mathrm{yrs}$ & 42 & $15(35.71)$ & $1.14(0.55-2.34)$ & 0.731 & & \\
\hline $11+y r s$ & 45 & $17(37.78)$ & $1.24(0.62-2.50)$ & 0.545 & & \\
\hline $\begin{array}{l}\text { Termsof } \\
\text { Employment }\end{array}$ & & & & 0.0533 & & \\
\hline $\begin{array}{l}\text { Permanent \& } \\
\text { Pensionable }\end{array}$ & 133 & $53(39.85)$ & ref. & & ref. & \\
\hline Temporary/Fixed & 72 & $25(34.72)$ & $0.80(0.44-1.46)$ & 0.471 & $\begin{array}{l}0.92(0.41- \\
2.06)\end{array}$ & 0.848 \\
\hline Casually Employed & 21 & $3(14.29)$ & $0.25(0.07-0.90)$ & 0.033 & $\begin{array}{c}0.46(0.10- \\
2.01)\end{array}$ & 0.3 \\
\hline Spouse Employment & & & & 0.3289 & & \\
\hline Employed & 109 & $34(31.19)$ & ref. & & & \\
\hline Unemployed & 65 & $25(38.46)$ & $1.38(0.72-2.62)$ & & & \\
\hline $\begin{array}{l}\text { Substance Use by } \\
\text { Family Member }\end{array}$ & & & & $<0.001$ & & \\
\hline No & 118 & 25 (21.19) & ref. & & ref. & \\
\hline Yes & 111 & $55(49.55)$ & $3.65(2.05-6.51)$ & & $\begin{array}{l}2.88(1.33- \\
6.21)\end{array}$ & 0.007 \\
\hline $\begin{array}{l}\text { Substance Use by } \\
\text { Colleagues }\end{array}$ & & & & $<0.001$ & & \\
\hline No & 84 & $10(11.90)$ & ref. & & ref. & \\
\hline Yes & 113 & $58(51.33)$ & $7.80(3.66-$ & $<0.001$ & $4.59(1.95-$ & $<0.001$ \\
\hline
\end{tabular}




\section{Ever experienced stressful} event

\begin{tabular}{lccccc} 
No & 74 & $13(17.57)$ & ref. & ref. & \\
Yes & 141 & $60(42.55)$ & $3.48(1.75-6.90)$ & $1.77(0.73-4.29)$ & 0.206 \\
\hline
\end{tabular}
Significant results are presented in bold fonts $\mathrm{uOR}=$ Unadjusted Odd Ratio aOR= Adjusted Odd Ratio * Fischer exact test

This study found that HCW with a family member who uses a substance was associated with lifetime substance use(Table 1.3)

Similar observations were observed on substance use in the past 12 months. A higher proportion of male health care workers were found to have ever used all substances in the past 12 months in comparison to females. Significant difference was observed in alcohol and tobacco use.

\section{Prevalence of Substance Use}

The study's second objective was to determine the prevalence of substance use. Prevalence was calculated based on the sample with the characteristic of interest (Ever used substance in lifetime). It was found that slightly more than a third of the participants had reported lifetime use of a substance $(83,35.02 \%)$. Alcohol was the most used substance $(78,33.05 \%)$, followed by tobacco $(21,8.9 \%)$ and Khat $(13,5.51 \%)$. The quantitative results are supported by focus group discussions on the prevalence of substance use as shown in the excerpt:

"The problem is with us we cannot give names, we are grappling with the problem among our staff" HMT Member, Bungoma South sub County."Several staff do involve in substance use one way or the other, due to the stressful work environment 'HMT Member, Mt. Elgon sub County. 


\section{Patterns of Substance Use among health workers}

The patterns of Substance use was considered based on the ASSIST tool whereby substance use was considered with history of use in a lifetime, in the past 12 months and in the past 60 days

It was found that slightly more than a third of the participants had reported lifetime use of a substance $(83,35.02 \%)$. Alcohol was the most used substance $(78,33.05 \%)$, followed by tobacco $(21,8.9 \%)$ and Khat $(13,5.51 \%)$. Table 1.4 .

Substance use rate in the past one month was relatively higher among male HCWs compared to the female HCWs for all categories apart from the inhalant solvents with significant difference observed for alcohol and tobacco use. Similar findings were observed on studies done on Health Care Workers [16] and the general population [7]

This study reported less than $25 \%$ of alcohol use and less than $5 \%$ of other substance use for the past 12 and one month. The study findings on alcohol use by HCWs was similar to a study done in Kenya [16] and Ethiopia among undergraduate medical students that reported alcohol use prevalence of $22 \%$ [15]. 
Table 1.4. Lifetime Prevalence of Substances Use Categorized by type of Substance used

\begin{tabular}{|c|c|c|}
\hline Characteristic $(n=237)$ & $\mathbf{N}$ & $\%(95 \% \mathrm{CI})$ \\
\hline \multicolumn{3}{|c|}{ Ever Used any substance? } \\
\hline No & 154 & $64.98(58.64-70.83)$ \\
\hline Yes & 83 & $35.02(29.17-41.36)$ \\
\hline \multicolumn{3}{|c|}{ Alcohol $(n=236)$} \\
\hline $\mathrm{No}$ & 158 & $66.95(62.07-74.11)$ \\
\hline Yes & 78 & $33.05(25.89-37.93)$ \\
\hline \multicolumn{3}{|c|}{ Tobacco $(n=236)$} \\
\hline No & 215 & $91.1(87.43-94.71)$ \\
\hline Yes & 21 & $8.9(5.29-12.57)$ \\
\hline \multicolumn{3}{|c|}{ Inhalants/Solvents(sniffing) $(\mathrm{n}=236)$} \\
\hline No & 232 & $98.31(96.02-99.58)$ \\
\hline Yes & 4 & $1.69(0.42-3.98)$ \\
\hline \multicolumn{3}{|l|}{ Khat $(n=236)$} \\
\hline No & 223 & $94.49(91.57-97.35)$ \\
\hline Yes & 13 & $5.51(2.64-8.43)$ \\
\hline \multicolumn{3}{|c|}{$* *$ Prescription Drugs $(\mathbf{n}=\mathbf{2 3 6})$} \\
\hline No & 225 & $95.34(92.11-97.67)$ \\
\hline Yes & 11 & $4.66(2.33-7.89)$ \\
\hline \multicolumn{3}{|c|}{$\begin{array}{l}\text { Illicit hard drugs(Bhang, marijuana } \\
\qquad(\mathrm{n}=236)\end{array}$} \\
\hline No & 227 & $96.19(93.20-98.27)$ \\
\hline Yes & 9 & $3.81(1.73-6.80)$ \\
\hline \multicolumn{3}{|c|}{ Other Drugs $(\mathrm{n}=\mathbf{2 3 1})$} \\
\hline No & 228 & 98.7 (96.02-99.58) \\
\hline Yes & 3 & $1.3(0.42-3.98)$ \\
\hline
\end{tabular}


Table 1.5. Substance use in the lifetime among HCWs and its association by gender

\begin{tabular}{|c|c|c|c|c|c|}
\hline \multirow{2}{*}{ Characteristic } & \multicolumn{4}{|c|}{ Gender } & \multirow{2}{*}{$\begin{array}{l}\text { Bivariate } \\
\text { analysis }\end{array}$} \\
\hline & $\mathbf{N}$ & $\%$ & Female & Male & \\
\hline Alcohol & & & & & $* p$ value \\
\hline No & 158 & 67.2 & $106(67.1 \%)$ & $52(32.9)$ & $<0.001$ \\
\hline Yes & 77 & 32.8 & $29(37.6 \%)$ & $48(62.3 \%$ & \\
\hline $\begin{array}{l}\text { Tobacco (smoking/ } \\
\text { ingestion) }\end{array}$ & & & & & 0.0009 \\
\hline No & 214 & 91.1 & $131(61.2 \%)$ & $83(38.8 \%)$ & \\
\hline Yes & 21 & 8.9 & $17(80.9 \%)$ & $4(19.0 \%)$ & \\
\hline \multicolumn{6}{|l|}{ Inhalants/Solvents(sniffin } \\
\hline No & 232 & 98.3 & $133(56.1 \%)$ & $98(41.3 \%)$ & 0.9457 \\
\hline Yes & 4 & 1.7 & $2(0.84 \%)$ & $2(0.84 \%)$ & \\
\hline $\begin{array}{l}\text { MiraaKhat(chewable } \\
\text { stimulant) }\end{array}$ & & & & & 0.0065 \\
\hline No & 222 & 94.5 & $133(59.9 \%)$ & $89(40.1 \%)$ & \\
\hline Yes & 13 & 5.5 & $2(15.3 \%)$ & $11(84.6 \%)$ & \\
\hline \multicolumn{6}{|l|}{ **Prescription Drugs } \\
\hline No & 225 & 95.3 & $132(55.9 \%)$ & $92(38.9 \%)$ & 0.1125 \\
\hline Yes & 11 & 4.7 & $2(0.84 \%)$ & $8(3.3 \%)$ & \\
\hline $\begin{array}{l}\text { Illicit hard drugs(Bhang, } \\
\text { marijuana) }\end{array}$ & & & & & 0.0901 \\
\hline No & 227 & 98.7 & $133(56.3 \%)$ & $93(39.4 \%)$ & \\
\hline Yes & 3 & 1.3 & $2(0.84 \%)$ & $7(2.9 \%)$ & \\
\hline Other Drugs & & & & & 0.6904 \\
\hline No & 227 & 98.7 & $131(57.7 \%)$ & $96(42.3 \%)$ & \\
\hline Yes & 3 & 1.3 & $2(0.84 \%)$ & $1(0.4 \%)$ & \\
\hline
\end{tabular}

Substance Use in the Past 12 Months

The type of substances used in the past 12 months were alcohol 49 (20.85\%), prescription drug $8(3.43 \%)$ and Tobacco $8(3.42 \%)$ and Khat use $6(2.56 \%)$ (Table 1.6). All the substances were found to be used mostly by men as compared to women. However statistical significance difference was observed among those who used alcohol $(\mathrm{p}<0.001)$ and tobacco $(\mathrm{p}=0.011)($ Table 1.6) 
Table 1.6. Substance use in the past 12 months stratified by Gender

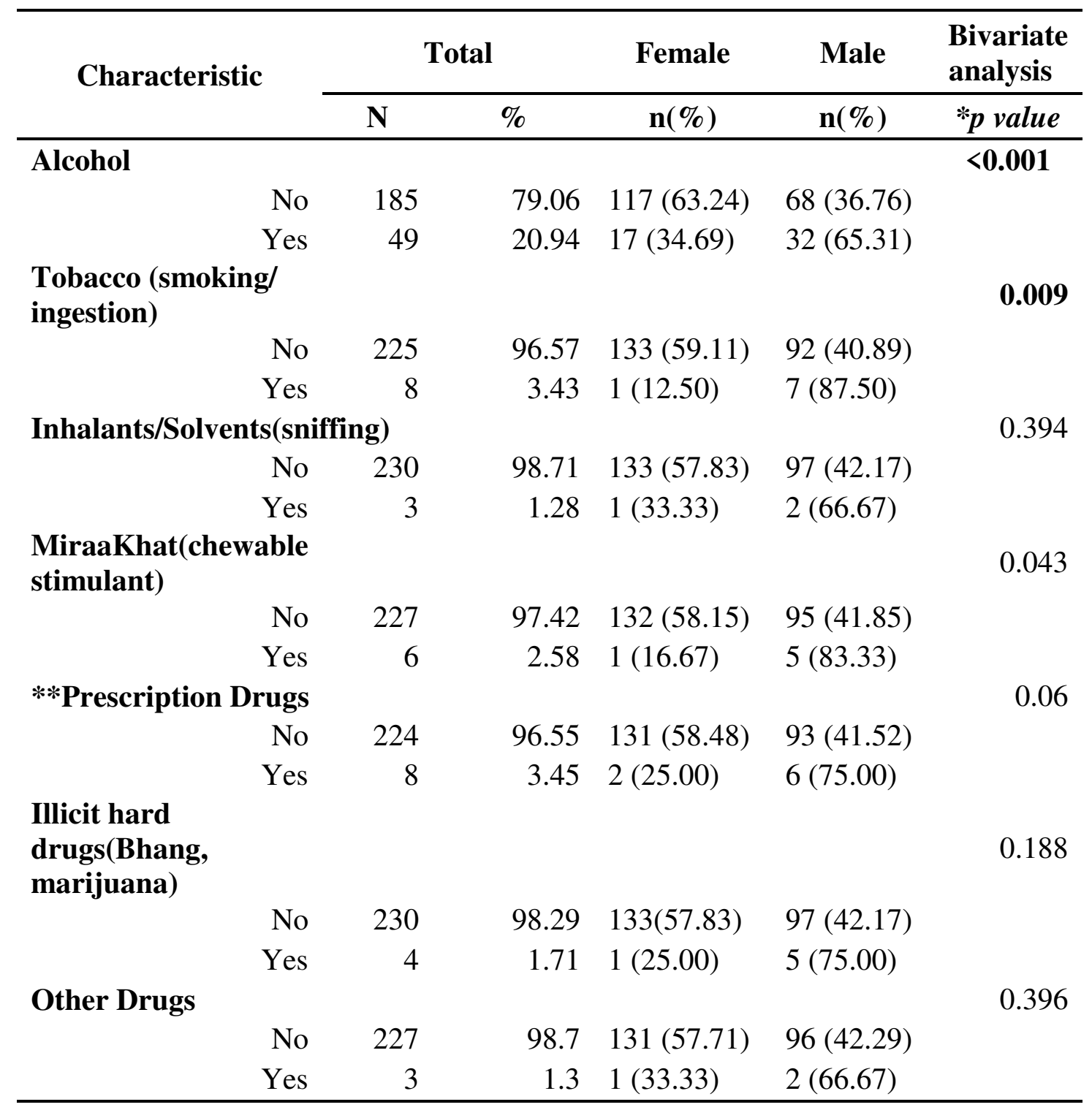

* Fischer exact test

**Prescription drugs(depressant and stimulant used for non medical purpose)

Trends of Substance use in the past 30 Days

Current substance usage was considered for use in the past 30 days. The top three leading types of substances currently used were Alcohol 36 (15.32\%), Tobacco $8(3.40 \%)$ and Prescription drugs $4(1.73 \%)$.The rest of substances use had rate of less than $1 \%$.All the substances were found to be used mostly by men as compared to women. However, statistical 
significance difference was observed among those who used alcohol $(\mathrm{p}<0.001)$ and tobacco ( $\mathrm{p}=0.009)$. (Table 1.7).

Table 1. 7. Substance use in the past 30 Days by Gender

\begin{tabular}{|c|c|c|c|c|c|c|}
\hline \multirow{2}{*}{\multicolumn{2}{|c|}{ Characteristic }} & \multicolumn{2}{|c|}{ Total } & \multirow{2}{*}{$\begin{array}{c}\text { Female } \\
\mathrm{n}(\%) \\
\end{array}$} & \multirow{2}{*}{$\frac{\text { Male }}{\mathrm{n}(\%)}$} & \multirow{2}{*}{$\begin{array}{l}\text { Bivariate } \\
\text { analysis } \\
{ }^{*} p \text { value }\end{array}$} \\
\hline & & $\mathbf{N}$ & $\%$ & & & \\
\hline \multicolumn{7}{|c|}{$\begin{array}{l}\text { Substance Use in past } 30 \\
\text { days }\end{array}$} \\
\hline \multirow[t]{3}{*}{ Alcohol } & & & & & & $<0.001$ \\
\hline & No & 198 & 84.62 & $123(62.12)$ & $75(37.88)$ & \\
\hline & Yes & 36 & 15.38 & $11(30.56)$ & $25(69.44)$ & \\
\hline \multirow[t]{3}{*}{ Tobacco } & & & & & & 0.009 \\
\hline & No & 226 & 96.58 & $133(58.85)$ & $93(41.15)$ & \\
\hline & Yes & 8 & 3.42 & $1(12.50)$ & $7(87.50)$ & \\
\hline \multicolumn{4}{|c|}{ Inhalants/Solvents(sniffing } & & & 0.839 \\
\hline & No & 231 & 99.14 & $132(57.14)$ & $99(42.86)$ & \\
\hline & Yes & 2 & 0.86 & $1(50.00)$ & $1(50.00)$ & \\
\hline \multicolumn{2}{|l|}{$\begin{array}{l}\text { MiraaKhat(chewable } \\
\text { stimulant) }\end{array}$} & & & & & 0.823 \\
\hline & No & 230 & 99.14 & $133(57.83)$ & $97(42.17)$ & \\
\hline & Yes & 2 & 0.86 & $1(50.00)$ & $1(50.00)$ & \\
\hline \multirow[t]{3}{*}{ Prescription Drugs } & & & & & & 0.193 \\
\hline & No & 226 & 98.26 & $130(57.52)$ & $96(42.48)$ & \\
\hline & Yes & 4 & 1.74 & $1(25.00)$ & $3(75.00)$ & \\
\hline \multicolumn{3}{|c|}{$\begin{array}{l}\text { Illicit hard drugs(Bhang, } \\
\text { marijuana) }\end{array}$} & & & & 0.835 \\
\hline \multirow{5}{*}{ Other Drugs } & No & 232 & 99.15 & $133(57.33)$ & $99(42.67)$ & \\
\hline & Yes & 2 & 0.85 & $1(50.00)$ & $1(50.00)$ & \\
\hline & & & & & & 0.838 \\
\hline & No & 229 & 99.13 & $131(57.21)$ & $98(42.79)$ & \\
\hline & Yes & 2 & 0.87 & $1(50.00)$ & $1(50.00)$ & \\
\hline
\end{tabular}

* Fischer exact test 


\section{Discussion}

This study adds to the knowledge on substance use among the health workers in Bungoma county Kenya which was not known. It contributes to the knowledge and highlights the important role of a family in substance use disorder prevention since health care workers who were male were more prone to substance use compared to females. This was consistent with Ding, (2014) assertion that a family member who uses substance has been found to be more likely to influence other members to use substances such as alcohol. Similar findings were observed by a study done in Ethiopia among medical students [15] and in Kenya among HCWs [16]

HCWs with a college degree were found to be associated lifetime substance use during the bivariate analysis compared to those with a certificate course. Similar findings were observed in a study done on HCWs in Kenya [16].Health care workers who were on casual employment were negatively associated with lifetime substance use compared to the HCWs who were on permanent and pensionable terms. The Kenya national campaign against drug abuse(NACADA) findings reported a higher percentage of high-income group in Kenya reported ever use of substance [7] and corroborates with the study's finding. Similar findings were observed by a study done in Kenya [16]

\section{Limitations}

The finding of this study cannot be generalized to the population of health workers in Kenya since it was drawn only from one county to explore patterns and correlates. This study was limited to prevalence and correlates of substance use and did not entail screening for evidence and was also limited in controlling the attitudes of the respondent, since respondents could have given socially acceptable answers to please the researcher (social desirable bias). 
Although respondent's confidentiality was assured during the data collection use of selfreporting approach may have influenced the outcome of this study due to the sensitivity of substance use.

\section{Conclusion}

Substance use among health workers is prevalent. Alcohol use had the highest prevalence while gender, use of substance by family member and close colleague were associated with substance use and found statistically significant. Socio-demographic factors on age, gender and peer influence was associated with substance among health workers in Bungoma County.

Considering that history of substance use by family member and peers influences substance use, calls for substance use preventive interventions such as sensitization at family level and among peers. The researcher recommends further in-depth study to get insights on substance abuse, dependence, reasons for substance use and how it affects health workers performance.

\section{Declarations}

This paper is our original work and has not been presented for a degree in any other university.

\section{Ethics approval and consent to participate}

Permission to conduct the research was obtained from the graduate school Kenyatta University, Kenyatta university ethical clearance committee, the National council for science \& technology (NACOSTI), and the county health department. The research instruments used were made anonymous and informed consent was sought from each respondent.To mitigate against breach of privacy and ethical concerns, the respondent were assured of privacy and requested to completed the self-report questionnaire individually in a secluded area to prevent 
respondents from answering questions as a team. The questionnaires included a statement of reassurance and confidentially for each respondent.

\section{Consent for publication}

The consent for publication was sought from Kenyatta, University Department of Community Health \& Epidemiology

\section{Availability of data and materials}

The data for the work can be obtained through a formal written request to the author at tkolongei@gmail.com

Funding: The principal investigator financed the cost of the entire research work in Bungoma County which included transport costs, payment for allowances for research assistants and the stationery and printing costs for the research work. No money was obtained from an institution.

\section{Competing interests}

The authors declare that they have no competing interests

\section{Authors Contribution}

TK Conceived this study and directed the research and conducted the analysis while JO and GC reviewed the manuscript and contributed to the background and writing and wrote the methods section. GC helped in revising the literature

\section{Acknowledgments}

This work was supported by Kenyatta University. The interpretations and conclusions are solely from the authors and in no way represent the position of the Ministry of Health republic of Kenya. We wish to sincerely thank the Bungoma county government, health department and the field staff who supported during the data collection period. Equally we like to thank all health workers that voluntarily participated in this study 


\section{References}

[1] WHO, Neuroscience of psychoactivesubstance use and dependence, Geneva: WHO, 2004.

[2] WHO, "Abuse(Abuse,alchohol,chemical,substance or phsychoactive substances," WHO, Geneva, 2016.

[3] B. Berk, "Effective Substance Abuse Prevention.Why it Matters," Centre for Applied Research Solutions, California, 2013.

[4] UNODC, “World Drug Report,” UNODC, New York, 2012.

[5] I. Olawole, "Substance use among adolescents in sub-Saharan Africa: A systematic review and meta-analysis.," South Africa Journal of Child Health, vol. Volume 2, pp. pp. 79-80., 2018.

[6] 2. NACADA, Rapid Situation Asseesement of Drugs and Substance Abuse, Nairobi: NACADA, 2017.

[7] "Assesing the Socio-Economic Impacts of Alchohol and Drug Abuse," NACADA, Nairobi, 2013.

[8] MOH-NASCOP, Kenya Health Workers Survey, Nairobi: MOH-NASCOP, 2005.

[9] W. M, "Should physcians by gatekeeprs of medical resources?," Journal of Medical Ethics, vol. 27, pp. 268-274, 2001. 
[10] O. P. Kahuthia Gathu, "Trends and Emerging drugs in Kenya," Journal of Applied Biosciences, vol. 67, pp. 5308-5325, 2014.

[11] A. A, The Effects of Alchohol and Drug abuse on work perfoamnce of employees in selected star related hospitals at Kenya coast, Mombasa: Kenyatta University, 2011.

[12] G. L. Kenna, "Risk factors for alchohol and and other drug use by health professionals," Substance Abuse Treatment, Prevention, and Policy, p. 3, 29 January 2008.

[13] N. C. A. D. Abuse, Report of the National Alcohol and Drug Abuse Conference, Nairobi: $\mathrm{MOH}, 2012$.

[14] R. Simiyu and J. Wakhungu, "Risk reduction strategies in Drug and Substance Abuse," Journal of International Academic Research for Multidisciplinary, vol. 2, pp. 234-240, 2014.

[15] A. A. Wakarri Deressa, "Substance use and its predictors among undergraduate medical students of Addis Ababa University in Ethiopia,” BMC, vol. 11, p. 660, 29 August 2011.

[16] A. M. M. A. Mokaya, "Substance Use among a Sample of Healthcare Workers," Journal of Psychoactive Drugs, vol. 1072, pp. 1-10, 2016. 


\section{Supplementary Files}

This is a list of supplementary files associated with this preprint. Click to download.

- StudyonSubstanceUseBungomaCountyResults.xlsx 